\title{
Relation between Family Functioning and Quality of Life among Family Caregivers of Patients with Terminal Cancer Hospitalized in General Wards
}

\author{
Miki Morishita-Kawahara1,2*, Takuya Kawahara3 ${ }^{3}$ Kiyoko Kamibeppu ${ }^{2,4}$ \\ ${ }^{1}$ Division of Gerontological Nursing, School of Nursing, Tokyo Women’s Medical University, Tokyo, Japan \\ ${ }^{2}$ Department of Family Nursing, Graduate School of Health Sciences and Nursing, Faculty of Medicine, The University of Tokyo, \\ Tokyo, Japan \\ ${ }^{3}$ Clinical Research Promotion Center, The University of Tokyo Hospital, Tokyo, Japan \\ ${ }^{4}$ QOL Research Center for Children and Family, The University of Tokyo, Tokyo, Japan \\ Email: ${ }^{\star}$ m-morisita@umin.ac.jp
}

How to cite this paper: Morishita-Kawahara, M., Kawahara, T. and Kamibeppu, K. (2020) Relation between Family Functioning and Quality of Life among Family Caregivers of Patients with Terminal Cancer Hospitalized in General Wards. Open Journal of Nursing, 10, 1233-1240. https://doi.org/10.4236/ojn.2020.1012089

Received: November 19, 2020 Accepted: December 27, 2020 Published: December 30, 2020

Copyright $\odot 2020$ by author(s) and Scientific Research Publishing Inc. This work is licensed under the Creative Commons Attribution International License (CC BY 4.0).

http://creativecommons.org/licenses/by/4.0/ (c) (i) Open Access

\begin{abstract}
Caring for a patient with terminal cancer poses difficulties for family caregivers. Although families of patients with cancer have been classified by type, little is known about the relation between family functioning and quality of life (QOL) in family caregivers. This study aimed to develop a typology of family functioning in family caregivers of patients with terminal cancer and then examine the relation between the family functioning and QOL of family caregivers. From December 2013 to August 2014, fifty-one family caregivers of patients with terminal cancer were recruited at three hospitals in Tokyo, Japan. Perceptions of family functioning were assessed with the Family Relationship Index, and its three subscores were classified into three groups by cluster analysis. Caregivers' QOL was measured with the Caregiver Quality of Life Index-Cancer. The average total FRI score among 51 caregivers was $8.5(\mathrm{SD}=2.8)$. Family functioning was categorized into three clusters: supportive $(\mathrm{n}=12)$, communicative $(\mathrm{n}=30)$, or conflictive $(\mathrm{n}=8)$. Their QOL was categorized into two groups: the communicative group, with relatively high confliction, showed high QOL comparable to the supportive group. Family functioning in the families of patients with terminal cancer hospitalized in general wards was not good. For improving the QOL of family caregivers, it may be important for the family members to express their feelings and distress if they have conflicts.
\end{abstract}

\section{Keywords}

Cluster Analysis, Family Caregivers of Terminal Cancer Patients, Family 
Functioning, General Wards, Quality of Life

\section{Introduction}

Family caregivers play an important role in providing support to patients with terminal cancer. Caregivers and other family members experience many difficulties during the challenging period of end-of-life care [1]. For example, while caring for patients with terminal cancer, they frequently encounter difficult decisions, and their roles in the family change. These may cause difficulties for family members to express their feelings and distress, which is related to impaired family functioning [2].

Family functioning has been linked to a variety of health outcomes. Good family functioning is related to a lower incidence of psychological disorders in family and bereaved caregivers [3]. Meanwhile, families in conflict tend to show a higher level of depression and anxiety [4] [5].

In addition to psychological disorders, quality of life (QOL) is considered an essential outcome for caregivers of patients with cancer. The concept of QOL in caregivers of patients with cancer includes mental and physical distress and social support [6]. Therefore, QOL captures the overall deterioration in caregivers, whereas the incidence of psychological illnesses captures mental-specific deterioration. Schuler et al. reported that families with poor family functioning can predict greater levels of individual psychosocial morbidity [7]. To the best of our knowledge, no previous studies have investigated the relation between family functioning and QOL in family caregivers.

The aims of this study were to 1) develop a typology of family functioning in family caregivers of patients with terminal cancer and 2) examine the relation between family functioning and QOL in family caregivers.

\section{Methods}

We operationally defined "patients with terminal cancer" as "inpatients diagnosed with cancer who could not undergo surgery or chemotherapy because of poor health conditions and whose treatment aimed at alleviation at the time of the investigation," and "care" as "services medical staff provide for patients and their family caregivers during hospitalization."

\subsection{Study Design and Participants}

We conducted a cross-sectional study from December 2013 to August 2014. We recruited family caregivers of patients with terminal cancer at three hospitals in Tokyo, Japan. We opted to conduct our survey in the gastroenterology ward in consideration of the high proportion $(>50 \%)$ of cancer deaths from digestive cancer in Japan [8]. The following criteria were observed in the recruitment: a) having a relative who was a terminal cancer patient aged $>20$ years; b) being 
perceived by the patient as the primary caregiver (or perceived by the family as the primary caregiver if the patient was unable to answer because of poor health); c) aged $>20$ years; d) judged by the head nurse as physically and mentally capable of participating in the survey.

\subsection{Procedures}

The head nurse in each ward chose the family caregivers who met the criteria. The nurse provided information to the admitted patients regarding the research objectives. For patients and family caregivers whom the researchers were allowed to see, the visit was conducted in the patient's hospital room; the researcher offered written and verbal explanation of the study. Written consent was obtained from each patient and family caregiver. Coupon books worth JPY 500 were given to the family caregivers. Family caregivers were asked to return the anonymous questionnaire either by mail or by using a mailing box in the ward.

All procedures performed in studies involving human participants were approved by the institutional review boards of University of Tokyo, Kyoundo hospital, and Cancer Institute hospital (approval numbers 10297, 10211, 101013); and in accordance with the ethical standards of the 1964 Declaration of Helsinki and its later amendments or comparable ethical standards.

\subsection{Measurements}

We measured the QOL of family caregivers using the Japanese version of the Caregiver Quality of Life Index-Cancer (CQOLC) [9] [10]. The CQOLC contains 21 items that comprise four subscales: psychological burden, positive emotions, financial burden, and disruption of daily living. A higher total score reflects a higher QOL.

We used the Japanese version of the Family Relationship Index (FRI) to measure family functioning [11] [12] [13]. The FRI is a well-validated measure of an individual's perception of family functioning. It contains 12 items that originated in the short form of the family environment scale [14]. The items comprise three aspects of family functioning: cohesion, expressiveness, and conflict. Each item is marked as true or false, with a total score ranging from 0 to 12 . A total score of 9 or higher indicates good family functioning.

\subsection{Analysis}

Demographic data of patients and caregivers were shown as $\mathrm{n}$ (\%) or mean (standard deviation [SD] and range). For assessing family perceptions among patients and their families, the FRI and its three subscales were chosen to form the clusters. Following Ozono et al. [4], we used a hierarchical cluster analytic approach employing Ward's method. Total CQOLC and FRI score were compared between clusters using analysis of variance (ANOVA) and following comparisons of a cluster with other clusters. We set a p-value less than 0.05 as statistically sig- 
nificant. Cluster analyses were performed using SPSS 23, and the other analyses were performed using SAS 9.4.

\section{Results}

Figure 1 summarizes the flow of the recruitment of the study sample. Of the 62 caregivers who completed questionnaires, $51(82 \%)$ completed and returned the questionnaire.

\subsection{Characteristics of Family Caregivers and Patients}

Table 1 summarizes the characteristics of the 51 caregivers and patients. In this study, caregivers' mean age was $59.7(\mathrm{SD}=15.0)$, and 43 caregivers $(84 \%)$ were female. The patients' mean age was $66.6(\mathrm{SD}=11.5)$, and 37 patients $(73 \%)$ were male. Common cancers were of the liver (45\%), spleen (24\%), and stomach (14\%).

\subsection{Family Functioning}

The average total FRI score among 51 caregivers was $8.5(\mathrm{SD}=2.8)$. The average scores of the subscales were as follows: cohesion $=3.2(\mathrm{SD}=1.2)$, expressiveness $=2.3(\mathrm{SD}=1.4)$, and conflict $=1.2(\mathrm{SD}=1.1)$. The average total FRI score was below the threshold for good family functioning $(<9)$. Among 51 caregivers, 22 $(44 \%)$ had a total FRI score of $<9$.

\subsection{Typology of Family Functioning and Association to Quality of Life in Family Caregivers of Patients with Terminal Cancer}

Table 2 shows the total and subscale scores for FRI, and the total score for CQOLC stratified by three clusters obtained by cluster analysis. Based on their subscale scores of FRI (cohesion, expressiveness, and conflict), we have defined

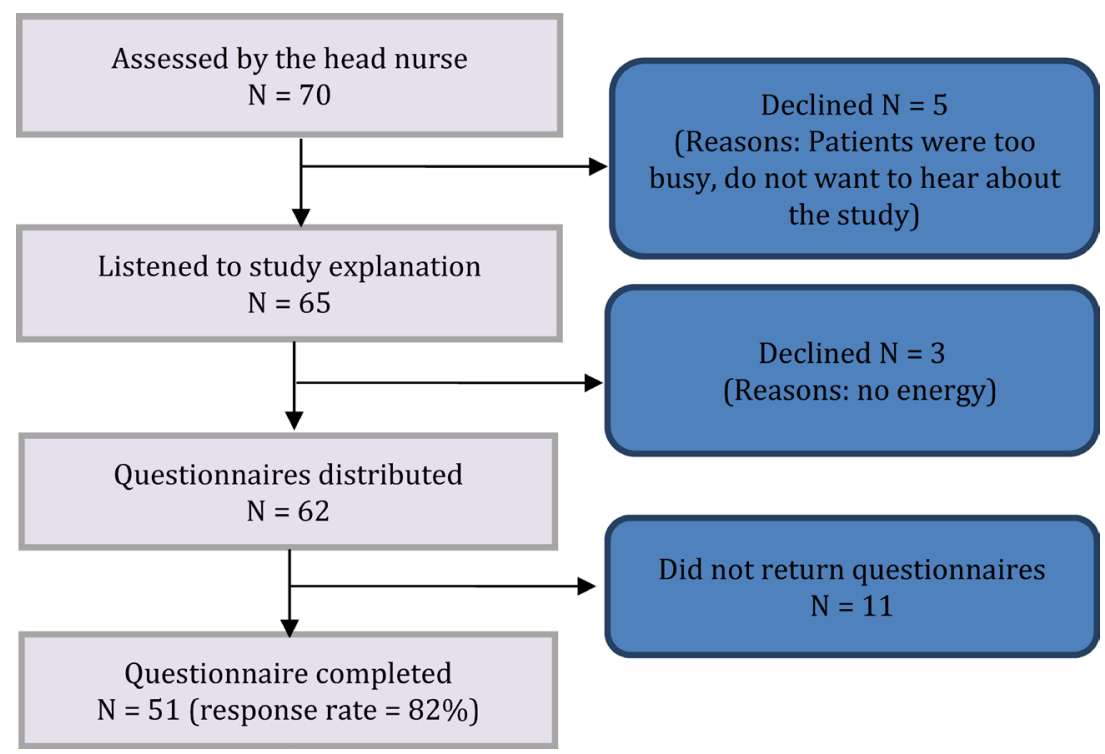

Figure 1. Flow of recruitment of study sample. 
Table 1. Characteristics of family caregivers and patients.

\begin{tabular}{|c|c|c|c|}
\hline Characteristics & & Caregivers & Patients \\
\hline Sex & Female & $43(84 \%)$ & $37(73 \%)$ \\
\hline Age & Years $^{\mathrm{a}}$ & $59.7 \pm 15.0(26-79)$ & $66.6 \pm 11.5(37-83)$ \\
\hline Marriage status & Married & $40(78 \%)$ & $43(84 \%)$ \\
\hline \multirow[t]{3}{*}{ Financial status } & Uncomfortable & $7(14 \%)$ & \\
\hline & Normal & $28(55 \%)$ & \\
\hline & Comfortable & $16(31 \%)$ & \\
\hline \multirow[t]{2}{*}{ Relationship } & Spouse & $35(69 \%)$ & \\
\hline & Child & $9(18 \%)$ & \\
\hline \multirow[t]{3}{*}{ Health status } & Not good & $10(20 \%)$ & \\
\hline & Average & $24(47 \%)$ & \\
\hline & Good & $17(32 \%)$ & \\
\hline \multirow[t]{5}{*}{ Cancer } & Stomach & & $7(14 \%)$ \\
\hline & Liver & & $23(45 \%)$ \\
\hline & Spleen & & $12(24 \%)$ \\
\hline & Colon & & $3(6 \%)$ \\
\hline & Gallbladder & & $6(12 \%)$ \\
\hline \multirow[t]{2}{*}{ Performance status } & 1 or 2 & & $24(47 \%)$ \\
\hline & 3 or 4 & & $27(53 \%)$ \\
\hline Time since diagnosis & Months $^{\mathrm{a}}$ & & $41.4 \pm 52.3(1-240)$ \\
\hline
\end{tabular}

a. Mean \pm SD (range).

Table 2. Comparison of individual perceptions of family functioning within the three-class structure and quality of life within the family types.

\begin{tabular}{cccccc}
\hline & $\begin{array}{c}\text { Supportive } \\
(\mathbf{n}=12)\end{array}$ & $\begin{array}{c}\text { Communicative } \\
(\mathbf{n}=30)\end{array}$ & $\begin{array}{c}\text { Conflictive } \\
(\mathbf{n}=\mathbf{8})\end{array}$ & $\begin{array}{c}\text { ANOVA } \\
\text { F-value }\end{array}$ & $\begin{array}{c}\text { ANOVA } \\
\text { P-value }\end{array}$ \\
\hline FRI cohesion & $3.7 \pm 0.5$ & $3.7 \pm 0.7$ & $1.0 \pm 0.5$ & 64.8 & $<0.001$ \\
FRI expressiveness & $1.0 \pm 0.7$ & $3.4 \pm 0.7$ & $0.5 \pm 0.5$ & 82.1 & $<0.001$ \\
FRI conflict & $0.4 \pm 0.7$ & $1.3 \pm 1.2$ & $1.6 \pm 1.2$ & 3.7 & 0.032 \\
FRI total & $8.3 \pm 1.5$ & $9.8 \pm 2.1$ & $3.9 \pm 1.0$ & 33.5 & $<0.001$ \\
CQOLC total score & $77.2 \pm 9.5$ & $74.9 \pm 13.5$ & $65.0 \pm 15.4$ & 2.3 & $0.107^{\mathrm{a}}$ \\
\hline
\end{tabular}

Abbreviations: ANOVA, analysis of variance; FRI, Family Relationship Index; CQOLC, Caregiver Quality

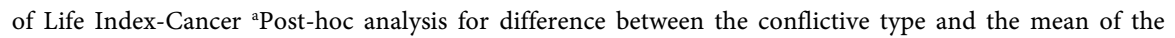
supportive and communicative types showed $\mathrm{p}=0.036$.

"supportive", "communicative", and "conflictive" types. The first type of family structure, which we named the "supportive" type $(\mathrm{n}=12)$, was characterized by high cohesion (average of $3.7, \mathrm{SD}=0.5$ ) and low conflict (average of $0.4, \mathrm{SD}=$ 0.7). Supportive families reported the highest CQOLC total score (average of $77.2, \mathrm{SD}=9.5)$. The "communicative" group $(\mathrm{n}=30)$ was characterized by high 
cohesion (average of 3.7, $\mathrm{SD}=0.7$ ) and high expressiveness (average of $3.4, \mathrm{SD}=$ 0.7 ) as well as high conflict (average of $1.3, \mathrm{SD}=1.2$ ). Communicative families reported the second-highest CQOLC total score (average of 74.9, SD = 13.5). The final type, "conflictive" type $(n=8)$, showed the highest conflict (average of $1.6, \mathrm{SD}=1.2$ ) and lowest CQOLC total scores (average of 65.0, $\mathrm{SD}=15.4$ ).

ANOVA showed that the total and subscale FRI scores significantly differed across the three groups. On the other hand, ANOVA did not demonstrate that the CQOLC total score did not differ across three groups. However as shown in Table 2, the conflictive group had lower CQOLC total score than supportive and communicative groups. Therefore, we conducted post-hoc analysis. Post-hoc analysis for differences in CQOLC total scores between the conflictive type and the mean of supportive and communicative types showed statistical significance $(\mathrm{p}=0.036)$. This means that when supportive and communicative groups were combined, it has higher CQOLC total score than conflictive group.

\section{Discussion}

Family caregivers of patients with terminal cancer have many difficulties, which affect their family functioning. This study, to our knowledge, is the first that clarified the family functioning of family caregivers of patients with terminal cancer and that assessed the relation between their family functioning and QOL. We found that, on average, family functioning was not high in the families of family caregivers of patients with terminal cancer and hospitalized in general wards. The assessment needs to be expanded to patients with various cancer sites and prognoses. Moreover, future studies should assess sex differences.

The novel finding of this study is that the clusters of family caregivers differed for family functioning and QOL. Family functioning was categorized into three clusters, based on the cluster analysis for their FRI total score. The three family functioning clusters were supportive, communicative, and conflictive groups. By comparing the CQOLC total score among three clusters, we found that when supportive and communicative groups were combined, it has higher CQOLC total score than conflictive group. The supportive group showed the highest QOL among three clusters. It was an expected result after the cluster analysis, because the supportive group gathers well and do not conflict within the family. Interestingly, the communicative group, with relatively high conflict, showed a high QOL comparable to the supportive group. This finding indicated that QOL can be maintained if cohesion is sufficient and family caregivers can express their feelings and distress.

Previous studies have classified families based on family functions: family caregivers of patients with advanced cancer [15], families with patients with an expected survival of one year or less [16], and families with patients with an expected survival of six months or less and from a palliative care population [17]. Our classification of family caregivers differed from these studies in terms of the number and characteristics of the clusters. Our and earlier findings strongly in- 
dicate that the classification of families by family functioning is not consistent across the prognosis or clinical stage of patients. Therefore, studies on various types of families are necessary.

Our study had several limitations. The first is selection bias. We included family caregivers who came to the hospital to see patients; therefore, their family functioning may appear to be high. Second, as a cross-sectional study, our study could not determine causal relations. Third, the sample size was not based on a statistical calculation.

\section{Conclusion}

In conclusion, family functioning in patients with terminal cancer and who were hospitalized in general wards was not good. In the communicative families that had conflicts but expressed their feelings and distress, QOL was as high as that in supportive families. Family members may need to express their feelings and distress if they have conflicts with one another, to improve the QOL of family caregivers.

\section{Acknowledgements}

We are sincerely grateful to the participants and staff of the participating hospitals for cooperating in this study.

\section{Funding}

This research did not receive any specific grant from funding agencies in the public, commercial, or not-for-profit sectors.

\section{Conflicts of Interest}

The authors declare no conflicts of interest regarding the publication of this paper.

\section{References}

[1] Huang, H.L., Chiu, T.Y., Lee, L.T., Yao, C.A., Chen, C.Y. and Hu, W.Y. (2012) Family Experience with Difficult Decisions in End-of-Life Care. Psycho-Oncology, 21, 785-791. https://doi.org/10.1002/pon.3107

[2] Kissane, D.W., Bloch, S., Dowe, D.L., Snyder, R.D., Onghena, P., McKenzie, D.P. and Wallace, C. (1996) The Melbourne Family Grief Study, I: Perceptions of Family Functioning in Bereavement. The American Journal of Psychiatry, 153, 650-658. https://doi.org/10.1176/ajp.153.5.650

[3] Kissane, D.W., Bloch, S., Onghena, P., McKenzie, D.P., Snyder, R.D. and Dowe, D.L. (1996) The Melbourne Family Grief Study, II: Psychosocial Morbidity and Grief in Bereaved Families. The American Journal of Psychiatry, 153, 659-666. https://doi.org/10.1176/ajp.153.5.659

[4] Ozono, S., Saeki, T., Inoue, S., Mantani, T., Okamura, H. and Yamawaki, S. (2005) Family Functioning and Psychological Distress among Japanese Breast Cancer Patients and Families. Support Care Cancer, 13, 1044-1050. https://doi.org/10.1007/s00520-005-0816-5 
[5] Hamano, J., Morita, T., Igarashi, N., Shima, Y. and Miyashita, M. (2020) The Association of Family Functioning and Psychological Distress in the Bereaved Families of Patients with Advanced Cancer: A Nationwide Survey of Bereaved Family Members. Journal of Pain and Symptom Management. (In Press)

https://doi.org/10.1002/pon.5539

[6] Hsu, T., Nathwani, N., Loscalzo, M., Chung, V., Chao, J., Karanes, C., Koczywas, M., Forman, S., Lim, D., Siddiqi, T., et al. (2019) Understanding Caregiver Quality of Life in Caregivers of Hospitalized Older Adults with Cancer. Journal of the American Geriatrics Society, 67, 978-986. https://doi.org/10.1111/jgs.15841

[7] Schuler, T.A., Zaider, T.I., Li, Y., Masterson, M., McDonnell, G.A., Hichenberg, S., Loeb, R. and Kissane, D.W. (2017) Perceived Family Functioning Predicts Baseline Psychosocial Characteristics in U.S. Participants of a Family Focused Grief Therapy Trial. Journal of Pain and Symptom Management, 54, 126-131. https://doi.org/10.1016/j.jpainsymman.2017.03.016

[8] Cancer Statistics in Japan 2019. https://ganjoho.jp/en/professional/statistics/brochure/2019 en.html

[9] Weitzner, M.A., Jacobsen, P.B., Wagner Jr., H., Friedland, J. and Cox, C. (1999) The Caregiver Quality of Life Index-Cancer (CQOLC) Scale: Development and Validation of an Instrument to Measure Quality of Life of the Family Caregiver of Patients with Cancer. Quality of Life Research, 8, 55-63.

https://doi.org/10.1023/A:1026407010614

[10] Ando, S., Harata, M., Weitzner, M.A., Kuji, M., Shimizu, M., Sato, K. and Miyashita, M. (2013) Reliability and Validity of Japanese Version Caregiver Quality of Life Index-Cancer (CQOLC). Palliative Care Research, 8, 286-292. https://doi.org/10.2512/jspm.8.286

[11] Noguchi, Y., Saito, S., Tezuka, I. and Nomura, N. (1991) Family Environment Scale (FES) Japanese Version: Translation and Statistical Assessment. Japanese Journal of Family Therapy, 8, 147-158.

[12] Kissane, D.W., Bloch, S., Burns, W.I., McKenzie, D. and Posterino, M. (1994) Psychological Morbidity in the Families of Patients with Cancer. Psychooncology, 3, 47-56. https://doi.org/10.1002/pon.2960030109

[13] Kissane, D.W., Bloch, S., Burns, W.I., Patrick, J.D., Wallace, C.S. and McKenzie, D.P. (1994) Perceptions of Family Functioning and Cancer. Psychooncology, 3, 259-269. https://doi.org/10.1002/pon.2960030403

[14] Moos, R.H. (1990) Conceptual and Empirical Approaches to Developing Family-Based Assessment Procedures: Resolving the Case of the Family Environment Scale. Family Process, 29, 199-208. https://doi.org/10.1111/j.1545-5300.1990.00199.x

[15] Nissen, K.G., Trevino, K., Lange, T. and Prigerson, H.G. (2016) Family Relationships and Psychosocial Dysfunction among Family Caregivers of Patients with Advanced Cancer. Journal of Pain and Symptom Management, 52, 841-849.e1. https://doi.org/10.1016/j.jpainsymman.2016.07.006

[16] Schuler, T.A., Zaider, T.I., Li, Y., Hichenberg, S., Masterson, M. and Kissane, D.W. (2014) Typology of Perceived Family Functioning in an American Sample of Patients with Advanced Cancer. Journal of Pain and Symptom Management, 48, 281-288. https://doi.org/10.1016/j.jpainsymman.2013.09.013

[17] Kissane, D.W., McKenzie, M., McKenzie, D.P., Forbes, A., O’Neill, I. and Bloch, S. (2003) Psychosocial Morbidity Associated with Patterns of Family Functioning in Palliative Care: Baseline Data from the Family Focused Grief Therapy Controlled Trial. Palliative Medicine, 17, 527-537. https://doi.org/10.1191/0269216303pm808oa 